\title{
Determining the causes of rolling stock derailment from the track using modern research methods
}

\author{
Andriy Kuzyshyn ${ }^{1,2,3^{*}}$, Andriy Batig ${ }^{3}$, Julia Sobolevska ${ }^{2}$, Sergei Kostritsa ${ }^{1}$, Lyudmila Ursulyak ${ }^{1}$, and Stepan Dovhaniuk ${ }^{1}$ \\ ${ }^{1}$ Dnipro National University of Railway Transport named after Academician V. Lazaryan, 49000 Dnieper, Ukraine \\ ${ }^{2}$ Lviv branch of Dnipro National University of Railway Transport named after Academician V. Lazaryan, 79052 Lviv, Ukraine \\ ${ }^{3}$ Lviv Research Institute of Forensic Science, 79000 Lviv, Ukraine
}

\begin{abstract}
The analysis of cases of rolling stock derailment from the track at PJSC «Ukrzaliznytsia» over the past 5 years has been carried out and their main types are given. It is noted that the rapid development and improvement of computer technology allows the use of computer and mathematical modelling in the study of cases of rolling stock derailment from the rail track, which makes it possible to take into account a combination of factors that have the main influence on the behavior of rolling stock when moving along the track. It has been established that the first step is the construction of a mathematical model of an object using a selected type of mathematical description: algebraic, differential, integral equations, discrete mathematics, set theory, and others. And the second step is the choice of a method for solving these models. The simulation methods are given, which, depending on the programming style, are divided into: procedural-oriented, object-oriented, logical-oriented, rule-oriented, and oriented to constraints. An objectoriented programming of a freight car has been developed, which will make it possible to evaluate its main dynamic indicators, in particular, indicators of stability from derailment. This in turn will facilitate the establishment of the main causes of rolling stock derailment from the rail track.
\end{abstract}

\section{Introduction}

In accordance with the Regulations [1], transport events during trains traffic and maneuvers that threaten the safety of traffic are classified according to characteristics as disasters (accidents with serious consequences), accidents and incidents.

At present, one of the main and most significant categories of an accident is rolling stock derailment, which has been analyzed for the last 5 years at PJSC «Ukrzaliznytsya» (Fig. 1).

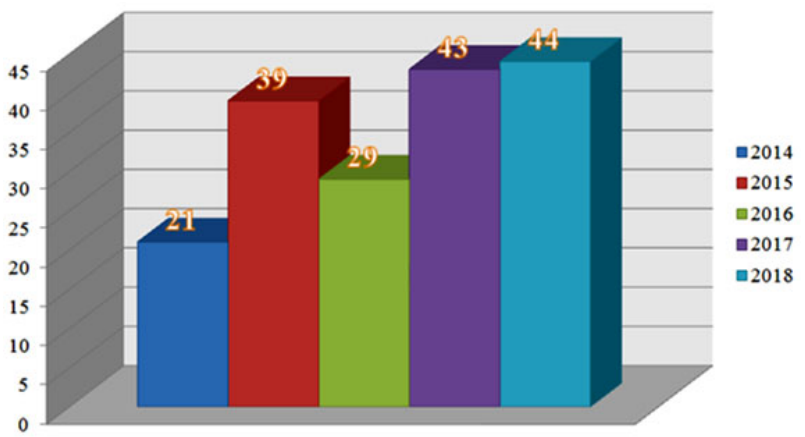

Fig. 1. The number of cases of rolling stock derailment on the railways of PJSC «Ukrzaliznytsya» for the last 5 years

In accordance with [2], all cases of rolling stock derailment can be divided into the following main types:
- derailment due to track disassembly (ousting by railhead flange of one rail because of its elastic inclination and, as a result, the second wheel falling into the middle of the track from another rail);

- derailment due to rolling of a wheel ridge on the railhead with subsequent falling of the second wheel of the same wheel-pair into the middle of the track);

- derailment due to unacceptable horizontal transverse curvature (shift) of a rail-sleeper grid by wheels of a defective bogie when the train is braked or because of its temperature release;

- derailment due to rolling of a cut ridge of a defective bogie at the turnout;

- derailment due to arrow cut;

- derailment due to rolling stock collision;

- derailment due to rail breakage.

It should be noted that the study of the process of rolling stock derailment and identification of causes that led to it is a rather complex, labor-intensive work, which requires high qualification of a scientist, considerable time consumption and in-depth research with the use of modern scientific tooling applied in the field of dynamics of mechanical systems.

The analysis of cases of rolling stock derailment shows that the causes of these derailments can be obvious (explicitly expressed), as well as non-obvious (not explicitly expressed).

In this case, «hidden» causes may be conditioned by the simultaneous coincidence of a number of factors that

Corresponding author: kuzyshyn1993@gmail.com 
form the most adverse (worst) combination of circumstances that have developed in a certain state of the rolling stock unit and the section of the track where derailment occurred.

In order to take into account the impact of a number of different parameters and to determine the most significant of them in relation to the circumstances of rolling stock derailment, it is necessary to use methods of mathematical and computer simulation.

The use of these methods will allow to assess the force impact of rolling stock and the track, to set limit values of a plurality of parameters for both rolling stock and the track for the possibility of preventing railway transport incidents and ensuring traffic safety.

\section{Analysis of literary sources and problem statement}

A considerable amount of scientific works is devoted to the research of rolling stock dynamics with the help of mathematical models.

Academician V.A. Lazaryan first applied methods of mathematical modeling to study the stability of undisturbed train traffic, forced oscillations of locomotives and cars, as well as stationary and transitional modes of trains movement [3].

Also, among well-known works, one should highlight the work of Romen Yu.S. [4], where the results of rolling stock dynamics with the use of computation were given. However, in this paper, the mathematical model has been simplified, which gave rise to doubts about full adequacy of the model as for the actual process of interaction of rolling stock with the track.

Particular attention deserves the work of Yong $\mathrm{He}$ [5], which proposed the method of object-oriented modeling that can be used to predict some aspects of dynamic behavior of rolling stock. In simulation of each object behavior, a virtual prototype of rolling stock was formed, and the result of the simulation gave the opportunity to determine the parameters of rolling stock interaction with the track. However, this method does not take into account accidental nature of track unevenness, which has a major impact on dynamic parameters of rolling stock.

In paper [6], the authors determined the impact of rail track unevenness on dynamic forces in the contact wheel-rail. Two two-dimensional and three-dimensional numerical models have been developed that describe the process of interaction of rolling stock with the railway track. The disadvantage of this research is that when the difference in unevenness between the right and left rails increases, the results obtained in simulation process differed significantly from experimental ones.

In paper [7], when modeling rolling stock dynamics, the model has been developed that describes threedimensional dynamics of rolling stock. For simulating rolling stock dynamics, Matlab-Simulink and Adams Rail graphic environments of model simulation were used.

Also, it should be noted that in Lviv Research Institute of Forensic Expertise, cases of rolling stock derailment are analyzed with the approaches developed by D.Sc. Sokol E.M. [8-9]. The verification of these approaches in practice has confirmed the possibility of their application in cases of rolling stock derailment due to the following causes: the presence of significant difference in the diameter of wheels in car wheel-pairs, thin wheel ridges, not-standard distance between inner faces of wheels, significant longitudinal and transverse gaps between a side frame of a bogie and an axlebox.

To study the dynamic characteristics of freight cars, one can use the model that was developed at Moscow State University of Railways [10]. This model is spatial and takes into account a considerable part of rolling stock parameters, however, when simulating interaction of a wheel ridge with the inner face of the railhead, the origin of guiding force is not taken into account, which may lead to unreliable estimation of power interaction of rolling stock with the track.

Significant contribution to the development of the theory of rolling stock interaction with the track was posited by the scientists of the European Union, as it is depicted in the works [11-17].

The use of mathematical models when studying dynamics of modern rolling stock is depicted in works [18-19]. The authors' model of diesel train DPKr-2 allows to take into account a certain number of its parameters, but does not take into consideration the change in thermodynamic processes occurring in pneumatic springs of a car while running along the track, which has a random change in unevenness both in vertical and horizontal planes.

Consequently, for the present time, a lot of programs and software complexes have been developed for computer experiments on the study of rolling stock dynamics that allow perform realistic imitation of railway transport behavior while running on the railway track. Examples of foreign software packages can be: ADAMS/Rail, Medyna, Nucars, Simpack and Vampire. For studying with the help of the method of mathematical modeling of dynamic loading of cars, there are also software complexes «Dynamics of Rail Vehicles» («DYNRAIL») and «Universal Mechanism».

However, the use of existing mathematical models and software complexes does not allow to depict in full measure the behavior of power interaction of rolling stock and the track and take into account the simultaneous set of different parameters of rolling stock running gear and the track.

\section{Purpose and objectives of the research}

The purpose of this work is to improve the mathematical model of a freight car and to develop object-oriented programming, which will allow to assess the main dynamic parameters of a car, in particular, indices of stability against derailment and to determine the main causes of car derailment in the presence of non-obvious (not explicitly expressed) reasons.

Research objectives: 
- analyze the calculation scheme of a freight car in $Z X$, $Y X, Z Y$ planes;

- to improve the mathematical model of a freight car taking into account the guiding force;

- to develop object-oriented programming for the study of the process of power interaction of a freight car with the track.

\section{Investigation of power interaction of a freight car with the rail track}

The main method of studying complex processes and systems today is a computational experiment with computer simulation. This concept was introduced by Academician AA Samara as a method and technology of the research based on the construction and analysis of a computer model of an object being studied.

The first step of computer simulation is to construct a mathematical model of an object with the help of the chosen type of mathematical description: algebraic, differential, integral equations, discrete mathematics, set theory, and others.

The second step of computer simulation is the choice of the method of these models developing. This method should be the method of approximate or accurate computing, which, in turn, can be algorithmic and implemented on a computer. The implementation of a computational experiment can be either in the form of a finished, already known program or a program package, or a new program, compiled in the chosen programming language.
After calculations, the stage of processing, analysis and study of the results comes, as well as their use for correcting the computational experiment and obtaining conclusions about the behavior of the object of research.

System simulation technology includes the sequence of such actions (Fig. 2):

1. Setting the goal of modeling;

2. Analysis of the object of modeling and obtaining its known properties;

3. Analysis of obtained properties in terms of the goal of modeling, determination of essential features;

4. Formalization of the initial problem;

5. Construction of a mathematical model;

6. Model calculation;

7. Analysis of the obtained model for conformity with the purpose of simulation;

8. Checking the adequacy of the model;

9. Implementation of calculation.

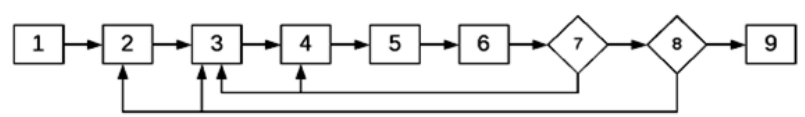

Fig. 2. Stages of constructing systems' models and their interconnections

In this case, the object of the study is a freight car, which spatial computation scheme is given at (Fig. 3-5).

The spatial computation scheme of a freight car consists of 11 solids (bodywork, four side frames, four wheel-pairs and two truck bolsters) [10].

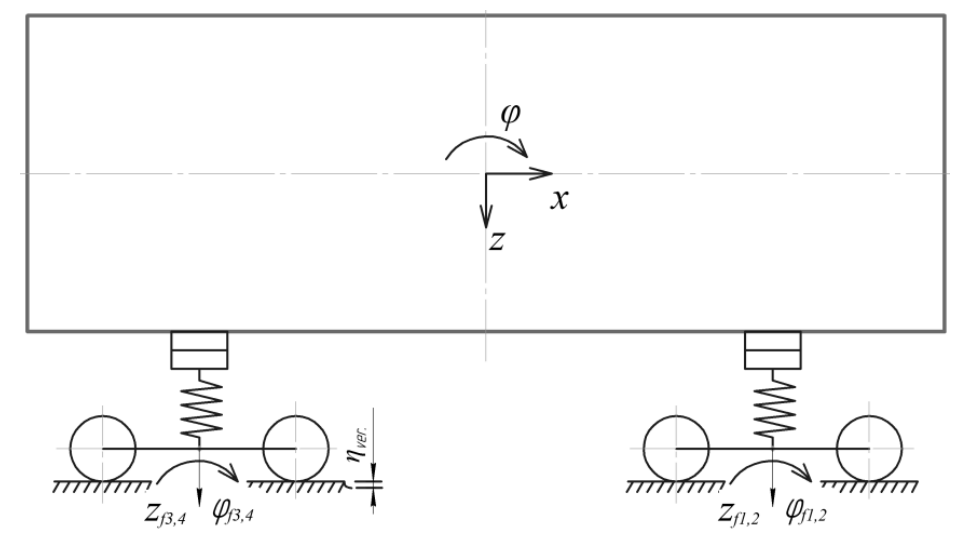

Fig. 3. Computation scheme of a freight car in plane $Z X$

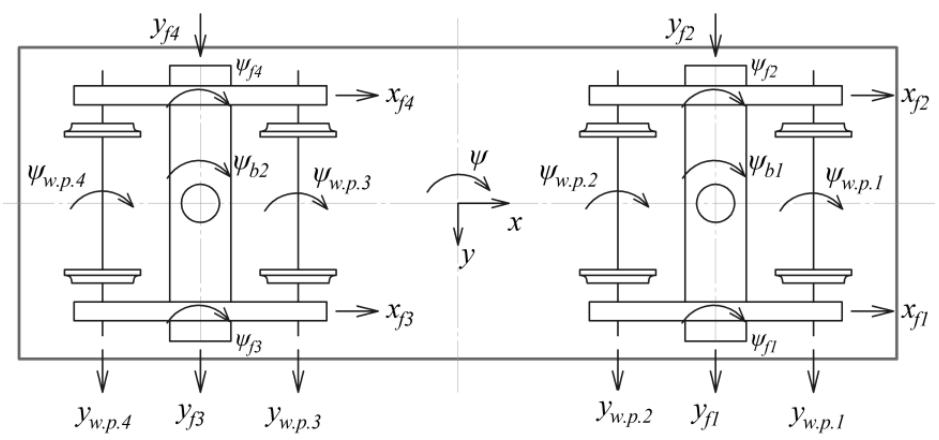

Fig. 4. Computation scheme of a freight car in plane $Y X$ 


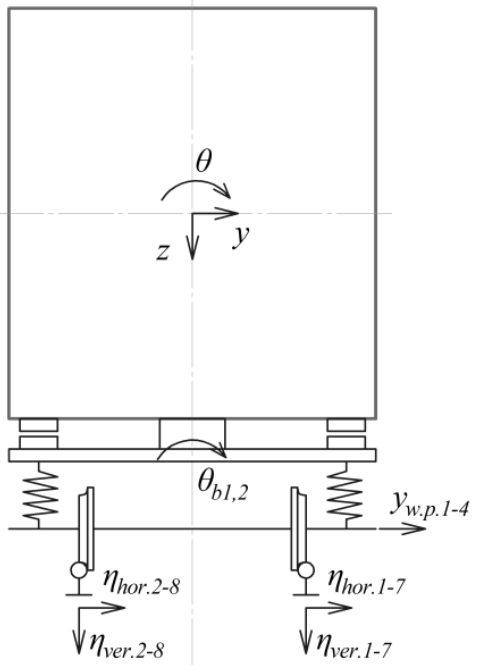

Fig. 5. Computation scheme of a freight car in plane $Z Y$

$z, y, x, \varphi, \psi, \theta$ - generalized body coordinates; $z_{f i}, y_{f i}, x_{f i}, \varphi_{f i}, \psi_{f i}$ - generalized coordinates of a bogie frame

( $i=1-2$ frame number of the bogie); $y_{\text {w.p.j. }}, \psi_{\text {w.p.j }}$ - generalized coordinates of wheel-pairs ( $j=1-4$ wheel-pair number),

$\theta_{b k}, \psi_{b k}$ - coordinates of truck bolsters ( $k=1,2$ number of truck bolster); $\eta_{\text {ver.l }}, \eta_{h o r . l}-$ vertical and horizontal unevenness under wheel-pairs of a freight car $(l=1-8$ wheel-pair number $)$

On the basis of constructed spatial calculating scheme of a freight car, its mathematical model was compiled [10]. This mathematical model has been improved taking into account the guiding force and consists of 30 differential equations of the second order.

Some assumptions were made, namely:

- the body, truck bolsters, sidewalls and wheel-pairs were considered as absolutely solid bodies, since their stiffness significantly exceeds the rigidity of the elastic elements that connect them;

- fluctuations of bouncing, lateral displacement, twitching, galloping, lateral swinging, twisting are considered;
- the values of stiffness are considered to be the same for corresponding elements of spring suspension of different bogies and wheel-pairs;

- the elastic forces are considered to act on the axis of the corresponding elastic element;

- the stiffness in the contact point of a wheel and the rail is not taken into account;

- a wheel-pair and interacting with it mass of the track move jointly.

Here are some basic differential equations of the mathematical model of a freight car, which describe the process of its power interaction with the track.

Body

$$
\begin{aligned}
& m \ddot{x}+\sum_{j=1}^{5} P_{\mathrm{f} x j}^{\prime}+\sum_{j=1}^{5} P_{\mathrm{f} x j}^{\prime \prime}+\sum_{j=1}^{5} P_{\mathrm{s} x j}^{\prime}+\sum_{j=1}^{5} P_{\mathrm{s} x j}^{\prime \prime}+N_{x 1}+N_{x 2}-N_{x 3}-N_{x 4}+N_{x 5}+N_{x 6}-N_{x 7}-N_{x 8}=0 \\
& m H \ddot{\theta}+m \ddot{y}+\sum_{j=1}^{7} P_{\mathrm{f} y j}^{\prime}+\sum_{j=1}^{7} P_{\mathrm{f} y j}^{\prime \prime}+\sum_{j=1}^{7} P_{\mathrm{s} y j}^{\prime}+\sum_{j=1}^{7} P_{\mathrm{s} y j}^{\prime \prime}+\sum_{j=1}^{8} T_{y j}=0 \\
& m \ddot{z}+\sum_{j=1}^{5} P_{\mathrm{f} z j}^{\prime}+\sum_{j=1}^{5} P_{\mathrm{f} z j}^{\prime \prime}+\sum_{j=1}^{5} P_{\mathrm{s} z j}^{\prime}+\sum_{j=1}^{5} P_{\mathrm{s} z j}^{\prime \prime}+\sum_{j=1}^{8} N_{z j}-m g=0 \\
& m H \ddot{y}+\left(m H^{2}+J_{\text {sup } x}\right) \ddot{\theta}+R_{\text {b1 }} e_{\text {c.p. } 1}+R_{\text {b2 }} e_{\text {c.p. } 2}+R_{\text {bear. } 1} B_{1}-R_{\text {bear. } 2} B_{2}+R_{\text {bear } 3} B_{3}-R_{\text {bear. } 4} B_{4}=0 \\
& J_{\text {sup. } y} \ddot{\varphi}+P_{\mathrm{f} z 1}^{\prime}\left(L_{1}+e_{\mathrm{f} 1}^{\prime}\right)+P_{\mathrm{f} z 2}^{\prime}\left(L_{1}+e_{\mathrm{f} 2}^{\prime}\right)+P_{\mathrm{f} z 3}^{\prime}\left(L_{1}-e_{\mathrm{f} 3}^{\prime}\right)+P_{\mathrm{f} z 4}^{\prime}\left(L_{1}-e_{\mathrm{f} 4}^{\prime}\right)+P_{\mathrm{f} z 5}^{\prime} L_{1}+P_{\mathrm{f} z 1}^{\prime \prime}\left(L_{1}+e_{\mathrm{f} 1}^{\prime \prime}\right)+P_{\mathrm{f} z 2}^{\prime \prime}\left(L_{1}+e_{\mathrm{f} 2}^{\prime \prime}\right)+ \\
& +P_{\mathrm{f} z 3}^{\prime \prime}\left(L_{1}-e_{\mathrm{f} 3}^{\prime \prime}\right)+P_{\mathrm{f} z 4}^{\prime \prime}\left(L_{1}-e_{\mathrm{f} 4}^{\prime \prime}\right)+P_{\mathrm{f} z 5}^{\prime \prime} L_{1}-P_{\mathrm{s} z 1}^{\prime}\left(L_{2}-e_{\mathrm{s} 1}^{\prime}\right)-P_{\mathrm{s} z 2}^{\prime}\left(L_{2}-e_{\mathrm{s} 2}^{\prime}\right)-P_{\mathrm{sz} 3}^{\prime}\left(L_{2}+e_{\mathrm{s} 3}^{\prime}\right)-P_{\mathrm{s} z 4}^{\prime}\left(L_{2}+e_{\mathrm{s} 4}^{\prime}\right)- \\
& -P_{\mathrm{s} z 5}^{\prime} L_{2}-P_{\mathrm{sz} 1}^{\prime \prime}\left(L_{2}-e_{\mathrm{s} 1}^{\prime \prime}\right)-P_{\mathrm{sz} 2}^{\prime \prime}\left(L_{2}-e_{\mathrm{s} 2}^{\prime \prime}\right)-P_{\mathrm{sz} 3}^{\prime \prime}\left(L_{2}+e_{\mathrm{s} 3}^{\prime \prime}\right)-P_{\mathrm{s} z 4}^{\prime \prime}\left(L_{2}+e_{\mathrm{s} 4}^{\prime \prime}\right)-P_{\mathrm{s} z 5}^{\prime \prime} L_{2}+N_{z 1}\left(L_{1}+E_{1}\right)+N_{z 2}\left(L_{1}+E_{2}\right)+ \\
& +N_{z 3}\left(L_{1}-E_{1}\right)+N_{z 4}\left(L_{1}-E_{4}\right)-N_{z 5}\left(L_{2}-E_{5}\right)-N_{z 6}\left(L_{2}-E_{6}\right)-N_{z 7}\left(L_{2}+E_{7}\right)-N_{z 8}\left(L_{2}+E_{8}\right)-\sum_{j=1}^{5} P_{\mathrm{fxj}}^{\prime} H_{1}- \\
& -\sum_{j=1}^{5} P_{\mathrm{f} x j}^{\prime \prime} H_{2}-\sum_{j=1}^{5} P_{\mathrm{s} x j}^{\prime} H_{3}-\sum_{j=1}^{5} P_{\mathrm{s} x j}^{\prime \prime} H_{4}-N_{x 1} H_{\mathrm{k} 1}-N_{x 2} H_{\mathrm{k} 2}+N_{x 3} H_{\mathrm{k} 3}+N_{x 4} H_{\mathrm{k} 4}-N_{x 5} H_{\mathrm{k} 5}-N_{x 6} H_{\mathrm{k} 6}+N_{x 7} H_{\mathrm{k} 7}+N_{x 8} H_{\mathrm{k} 8}=0
\end{aligned}
$$




$$
\begin{aligned}
& J_{\text {sup. } z} \ddot{\psi}+P_{\mathrm{fy} 1}^{\prime}\left(L_{1}+e_{\mathrm{f} 1}^{\prime}\right)+P_{\mathrm{fy} 2}^{\prime}\left(L_{1}+e_{\mathrm{f} 2}^{\prime}\right)+P_{\mathrm{fy} 3}^{\prime}\left(L_{1}-e_{\mathrm{f} 3}^{\prime}\right)+P_{\mathrm{fy} 4}^{\prime}\left(L_{1}-e_{\mathrm{f} 4}^{\prime}\right)+P_{\mathrm{fy} 5}^{\prime} L_{1}+P_{\mathrm{f} y 6}^{\prime}\left(L_{1}+e_{\mathrm{f} 6}^{\prime}\right)+P_{\mathrm{fy} 7}^{\prime}\left(L_{1}-e_{\mathrm{f} 7}^{\prime}\right)+ \\
& +P_{\mathrm{fy} 1}^{\prime \prime}\left(L_{1}+e_{\mathrm{f} 1}^{\prime \prime}\right)+P_{\mathrm{f} y 2}^{\prime \prime}\left(L_{1}+e_{\mathrm{f} 2}^{\prime \prime}\right)+P_{\mathrm{f} y 3}^{\prime \prime}\left(L_{1}-e_{\mathrm{f} 3}^{\prime \prime}\right)+P_{\mathrm{f} y 4}^{\prime \prime}\left(L_{1}-e_{\mathrm{f} 4}^{\prime \prime}\right)+P_{\mathrm{f} y 5}^{\prime \prime} L_{1}+P_{\mathrm{fy} y}^{\prime \prime}\left(L_{1}+e_{\mathrm{f} 6}^{\prime \prime}\right)+P_{\mathrm{f} y 7}^{\prime \prime}\left(L_{1}-e_{\mathrm{f} 7}^{\prime \prime}\right)- \\
& -P_{\mathrm{s} y 1}^{\prime}\left(L_{2}-e_{\mathrm{s} 1}^{\prime}\right)-P_{\mathrm{s} y 2}^{\prime}\left(L_{2}-e_{\mathrm{s} 2}^{\prime}\right)-P_{\mathrm{s} y 3}^{\prime}\left(L_{2}+e_{\mathrm{s} 3}^{\prime}\right)-P_{\mathrm{s} y 4}^{\prime}\left(L_{2}+e_{\mathrm{s} 4}^{\prime}\right)-P_{\mathrm{s} y 5}^{\prime} L_{2}-P_{\mathrm{s} y 6}^{\prime}\left(L_{2}-e_{\mathrm{s} 6}^{\prime}\right)-P_{\mathrm{s} y 7}^{\prime}\left(L_{2}+e_{\mathrm{s} 7}^{\prime}\right)- \\
& -P_{\mathrm{s} y 1}^{\prime \prime}\left(L_{2}-e_{\mathrm{s} 1}^{\prime \prime}\right)-P_{\mathrm{s} y 2}^{\prime \prime}\left(L_{2}-e_{\mathrm{s} 2}^{\prime \prime}\right)-P_{\mathrm{s} y 3}^{\prime \prime}\left(L_{2}+e_{\mathrm{s} 3}^{\prime \prime}\right)-P_{\mathrm{s} y 4}^{\prime \prime}\left(L_{2}+e_{\mathrm{s} 4}^{\prime \prime}\right)-P_{\mathrm{s} y 5}^{\prime \prime} L_{2}-P_{\mathrm{sy} 6}^{\prime \prime}\left(L_{2}-e_{\mathrm{s} 6}^{\prime \prime}\right)-P_{\mathrm{s} y 7}^{\prime \prime}\left(L_{2}+e_{\mathrm{s} 7}^{\prime \prime}\right)+ \\
& +T_{y 1}\left(L_{1}+d_{1}\right)+T_{y 2}\left(L_{1}+d_{2}\right)+T_{y 3}\left(L_{1}-d_{3}\right)+T_{y 4}\left(L_{1}-d_{4}\right)-T_{y 5}\left(L_{2}-d_{5}\right)-T_{y 6}\left(L_{2}-d_{6}\right)-T_{y 7}\left(L_{2}+d_{7}\right)- \\
& -T_{y 8}\left(L_{2}+d_{8}\right)-T_{\text {bear. } 1} B_{1}+T_{\text {bear. } 2} B_{2}-T_{\text {bear. } 3} B_{3}+T_{\text {bear. } 4} B_{4}-M_{\text {fric. } 1}+M_{\text {fric } .2}=0
\end{aligned}
$$

Truck bolsters

$$
\begin{gathered}
J_{x \mathrm{~b} 1} \ddot{\theta}_{\mathrm{b} 1}+N_{z 1} a_{1}-N_{z 2} a_{2}+N_{z 3} a_{3}-N_{z 4} a_{4}+\sum_{j=1}^{5} P_{\mathrm{f} z j}^{\prime} b_{\mathrm{f} j}^{\prime}-\sum_{j=1}^{5} P_{\mathrm{f} z}^{\prime \prime} b_{\mathrm{f} j}^{\prime \prime}-R_{\mathrm{bear} .1} B_{1}+R_{\mathrm{bear} .2} B_{2}-\sum_{j=1}^{7} P_{\mathrm{f} y j}^{\prime} h_{\mathrm{b} 1}-\sum_{j=1}^{7} P_{\mathrm{f} y j}^{\prime \prime} h_{\mathrm{b} 1}=0 \\
J_{z \mathrm{~b} 1} \ddot{\psi}_{\mathrm{b} 1}-N_{x 1} a_{1}+N_{x 2} a_{2}+N_{x 3} a_{3}-N_{x 4} a_{4}-\sum_{j=1}^{5} P_{\mathrm{f} x j}^{\prime} b_{\mathrm{f} j}^{\prime}+\sum_{j=1}^{5} P_{\mathrm{f} x j}^{\prime \prime} b_{\mathrm{f} j}^{\prime \prime}+T_{y 1} d_{1}+T_{y 2} d_{2}-T_{y 3} d_{3}-T_{y 4} d_{4}+P_{\mathrm{f} y 1}^{\prime} e_{\mathrm{f} 1}^{\prime}+ \\
+P_{\mathrm{f} y 2}^{\prime} e_{\mathrm{f} 2}^{\prime}-P_{\mathrm{f} y 3}^{\prime} e_{\mathrm{f} 3}^{\prime}-P_{\mathrm{f} y 4}^{\prime} e_{\mathrm{f} 4}^{\prime}+P_{\mathrm{f} y 6}^{\prime} e_{\mathrm{f} 6}^{\prime}-P_{\mathrm{f} y 7}^{\prime} e_{\mathrm{f} 7}^{\prime}+P_{\mathrm{fy} 1}^{\prime \prime} e_{\mathrm{f} 1}^{\prime \prime}+P_{\mathrm{fy} 2}^{\prime \prime} e_{\mathrm{f} 2}^{\prime \prime}-P_{\mathrm{f} y 3}^{\prime \prime} e_{\mathrm{f} 3}^{\prime \prime}-P_{\mathrm{fy} 4}^{\prime \prime} e_{\mathrm{f} 4}^{\prime \prime}+P_{\mathrm{f} y 6}^{\prime \prime} e_{\mathrm{f} 6}^{\prime \prime}-P_{\mathrm{f} y 7}^{\prime \prime} e_{\mathrm{f} 7}^{\prime \prime}+M_{\mathrm{fric} .1}+ \\
+T_{\text {bear. } 1} B_{1}-T_{\mathrm{bear} .2} B_{2}=0
\end{gathered}
$$

Sidewalls

$$
\begin{aligned}
& m_{f 1} \ddot{x}_{f 1}-T_{x 1}+T_{x 3}+T_{f x 1}+T_{f x 3}-\sum_{j=1}^{5} P_{\mathrm{f} x j}^{\prime}+N_{\mathrm{b} x 11}-N_{\mathrm{b} x 12}-N_{\mathrm{b} x 31}+N_{\mathrm{b} x 32}=0 \\
& m_{f 1} \ddot{y}_{f 1}-T_{y 1}-T_{y 3}+T_{f y 1}+T_{f y 3}-\sum_{j=1}^{7} P_{\mathrm{f} y j}^{\prime}-N_{\mathrm{b} y 11}+N_{\mathrm{b} y 12}-N_{\mathrm{b} y 31}+N_{\mathrm{b} y 32}=0
\end{aligned}
$$$$
J_{z f 1} \ddot{\psi}_{f 1}-T_{y 1} d_{1}+T_{y 3} d_{3}+T_{f y 1} l_{1}-T_{f y 3} l_{3}+P_{\mathrm{fx} 1}^{\prime} f_{\mathrm{f} 1}^{\prime}-P_{\mathrm{fx} 2}^{\prime} f_{\mathrm{f} 2}^{\prime}+P_{\mathrm{f} x 3}^{\prime} f_{\mathrm{f} 3}^{\prime}-P_{\mathrm{fx} 4}^{\prime} f_{\mathrm{f} 4}^{\prime}-P_{\mathrm{fy} 1}^{\prime} e_{\mathrm{f} 1}^{\prime}-P_{\mathrm{fy} 2}^{\prime} e_{\mathrm{f} 2}^{\prime}+P_{\mathrm{fy} 3}^{\prime} e_{\mathrm{f} 3}^{\prime}+
$$$$
+P_{\mathrm{f} y 4}^{\prime} e_{\mathrm{f} 4}^{\prime}-P_{\mathrm{f} y 6}^{\prime} e_{\mathrm{f} 6}^{\prime}+P_{\mathrm{f} y 7}^{\prime} e_{\mathrm{f} 7}^{\prime}-N_{\mathrm{b} y 11} l_{1}+N_{\mathrm{b} y 12} l_{1}+N_{\mathrm{b} y 31} l_{3}-N_{\mathrm{b} y 32} l_{3}=0
$$

Wheel-pairs

$$
\begin{gathered}
m_{w \cdot p .1} \ddot{y}_{w \cdot p .1}+F_{y 1}+F_{y 2}-T_{f y 1}-T_{f y 2}+R_{1} n_{1}-R_{2} n_{2}+N_{\mathrm{by} y 1}-N_{\mathrm{b} y 12}-N_{\mathrm{b} y 21}+N_{\mathrm{b} y 22}+N_{n a p 1} n_{f l a n .1}-N_{n a p 2} n_{f l a n .2}=0 \\
J_{z \text { w. } p .1} \ddot{\psi}_{w \cdot p .1}+F_{x 1} S_{1}-F_{x 2} S_{2}+T_{f x 1} D_{1}-T_{f x 2} D_{2}+N_{\mathrm{b} x 11} D_{1}-N_{\mathrm{b} x 12} D_{1}-N_{\mathrm{b} x 21} D_{2}+N_{\mathrm{b} x 22} D_{2}=0
\end{gathered}
$$

where $m$ - mass of the body and two truck bolsters; $J_{\text {sup. } x}, J_{\text {sup. } y}, J_{\text {sup. } z}-$ moments of body inertia relative to the axes $x, y, z$ which pass through the center of its weight; $P_{\mathrm{f} x}$ and $P_{\mathrm{s} x}$ - longitudinal reactions of springs of suspension kits for the first bogie in the train (index «f») and the second (index «s») bogie, respectively; $N_{x 1-8}-$ projections on the axle $x$ of normal forces acting between truck bolsters and friction wedges; $H$ - height of the gravity center of the body; $P_{\mathrm{fy}}$ and $P_{\mathrm{s} y}-$ transverse reactions of springs of suspension kits for the first and second bogies, respectively; $T_{y 1-8}-$ horizontal transverse force of friction between friction plates and wedges; $P_{\mathrm{fz}}$ i $P_{\mathrm{s} z}$ - vertical reactions of springs of suspension kits for the first and second bogies; $R_{\mathrm{b} 1}$ and $R_{\mathrm{b} 2}$ - vertical reactions on axial bearings; $e_{\text {c.p. } 1}$ and $e_{\text {c.p. } 2}$ - transverse displacements relative to the center of application of vertical reactions on axial bearings; $R_{\text {bear.14 }}$ - vertical reactions on sliders; $T_{\text {bear.14 }}$ - friction forces on sliders; $M_{\text {fric.1 }}$ and $M_{\text {fric. } 2}$ - moments of friction forces on axial bearings when truck bolsters turning relative to the body; $S_{1-8}$ - distance from the center of wheel-pairs' gravity to the points of a wheel and the rail contact; $D_{1-8}-$ distance from the gravity centers of wheel-pairs to the middle of the necks of axes; $R_{1-8}$ - vertical reactions between the wheel and the rail; $n_{1,2}$ - the taper of the wheel rim at points of contact; $N_{\text {nap }}$ - guiding force, which arises when working face of the flange is interacting with the side working face of the railhead; $n_{\text {flan. }}$ - the taper of the flange.

To calculate the spatial mathematical model and study the process of power interaction of a freight car with a rail track, the authors of the article developed object-oriented programming using computer environment Maple.

Maple is a software package, a computer algebra system (more precisely, a system of computer mathematics), focused on complex mathematical calculations, data visualization and modeling.

To solve this problem, a block diagram of the algorithm was constructed, which is shown at (Fig. 6). 


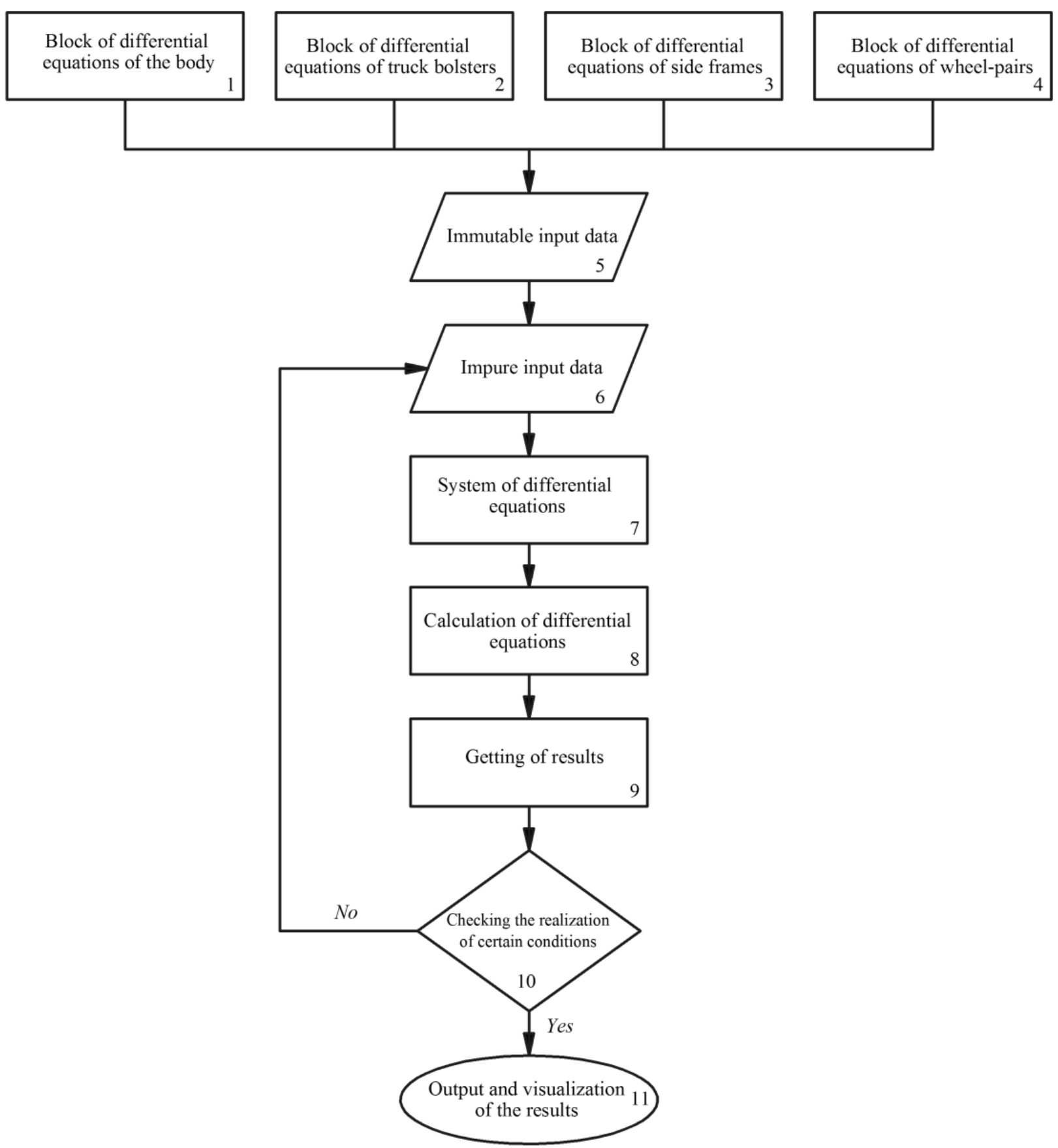

Fig. 6. Block diagram of the algorithm for studying the dynamic behavior of rolling stock in its interaction with the track

The block diagram of the algorithm depicts a sequence of blocks interconnected by arrows indicating the sequence of performance and the relationship between blocks. Inside the blocks their short content is written.

Input data are given by a separate block through an operator table $(F)$. Where $F$ is a table or an array.

Blocks of differential equations of a body, truck bolsters, side frames and wheel-pairs are described using the procedure. The procedure is called an application module that has an independent value and performs one or more operations, usually quite complex and different from the operations performed by the built-in operators and functions.
Sequence of the procedure call is as follows:

proc (parameterSequence) ::returnType; localSequence globalSequence; optionSequence; descriptionSequence; usesSequence; statementSequence end proc;

where parameterSequence - formal parameter declarations;

returnType - (optional) assertion on the type of the returned value;

localSequence - (optional) names of local variables;

globalSequence - (optional) names of global variables used in the procedure; 
optionSequence - (optional) names of procedure options;

descriptionSequence - (optional) sequence of strings describing the procedure;

usesSequence - (optional) names of modules or packages the procedure uses;

statementSequence - statements comprising the body of the procedure.

For analytical and numerical solution of differential equations in Maple software package, the dsolve command is used, which looks like:

$$
\text { dsolve( eqns, vars, option) }
$$

where eqns - is the system of equations with respect to non-invertible functions vars ;

option - additional conditions that allow to specify the method of solving the task.

Calculations of the mathematical model were carried out using numerical Runge-Kutta method of 4-5 orders.

Often, when modeling the dynamics of a rail train, there are cases of logic use, which is due to the closure of certain gaps or realization of certain conditions. To do this, an operator if is used which format looks like:

$$
\begin{gathered}
\text { if }<\text { conditional expression }>\text { then }<\text { statement sequence }> \\
\text { elif }<\text { conditional expression }>\text { then }<\text { statement sequence }> \\
\text { else }<\text { statement sequence }> \\
\text { end if }
\end{gathered}
$$

To visualize obtained results Maple allows to use computer graphic capabilities. The main command is plot in the standard library and does not require a previous call.

The structure of the command is as follows:

$$
\operatorname{plot}(\{\text { func1, func2...\}, } x=\mathrm{a} . . . \mathrm{b}, y=\mathrm{c} . . \mathrm{d} \text {, option })
$$

where func1, func2 - analytical expressions;

$$
\begin{aligned}
& \mathrm{x}=\mathrm{a} . . \mathrm{b} \quad-\text { interval of a variable change } x \\
& y=\mathrm{c} . . \mathrm{d} \quad-\quad \text { interval on the ordinate axis. }
\end{aligned}
$$

Thus, the mathematical model built in software package Maple allows:

- to study the process of power interaction of rolling stock with the rail track;

- to evaluate the main dynamic parameters of rolling stock, in particular, indices of its stability against derailment;

- to determine safe operating conditions when running on the rail track, which has deviations from its maintenance standards;

- to evaluate the impact of a plurality of different parameters and to determine the most significant of them in relation to circumstances of rolling stock derailment.

\section{Conclusions}

1. Analysis of the calculation scheme of a freight car, and its running gear, in particular, has shown that it can be used for the study of dynamic parameters, but the study of derailment cases requires improvement.

2. The mathematical model of a freight car has been improved, namely, the process of interaction of a wheel and the rail, which was realized with respect of guiding force at the moment when the wheel's flange presses on the lateral working flange of the rail.

3. On the basis of the improved mathematical model of a freight car, the block diagram of the algorithm for constructing a software product was developed, with the help of which it is possible to automate the study of the process of power interaction of a freight car with the rail track.

4. Using the step-by-step sequence of processes, which are depicted in the block diagram of the algorithm, object-oriented programming was developed with the help of Maple computer environment.

5. The use methods of mathematical and computer modeling will allow to assess the force impact of rolling stock and the track, to set limit values of a plurality of parameters for both rolling stock and the track for the possibility of preventing railway transport incidents and ensuring traffic safety.

\section{Bibliography}

1. Pologennya pro klasyfikatsiyu transportnykh podii na zaliznytshnomu transporti. Zatverdzheno Nakazom Ministerstva infrastruktury Ukrainy 03.07.2017 № 235. (2017) [in Ukrainian]

2. TSRB-0036 Metodychni vkazivky schodo poryadku sluzhbovoho rozsliduvannya prychyn skhodzhen rukhomoho skladu z reyok na zaliznytsiakh Ukrainy. Zatverdzheno Nakazom Ukrzaliznytsi 21.06.2012 №194-TSZ. (2012) [in Ukrainian]

3. V. A. Lazaryan Dinamika vagonov, Transport, $256 \mathrm{p}$, (1964) [in Russian]

4. Yu. S. Romen $O$ dvizhenii zheleznodorozhnoho ekipazha $v$ krivykh uchastkakh puti, Vestnik VNIIGT, 6 (1964) [in Russian]

5. He Y Object-Oriented Modeling and Simulation of Railway Vehicle Systems, Applied Mechanics and Materials, 26-28 900-904 c (2010)

6. J. Sadeghi, A. Khajehdezfuly, M. Esmaeili Investigation of rail irregularity effects on wheel/rail dynamic force in slab track: Comparison of two and three dimensional models. J Sound Vibration, 374 228-244 c (2016)

7. J. Auciello Determination of wheel/rail contact points in the simulation of a railway vehicle dynamics, WIT Transactions on Engineering Sciences, 62 261-270 c (2010)

8. E. N. Sokol Skhody $s$ relsov $i$ stolknoveniya podvizhnoho sostava (Sudebnaya ekspertiza. Elementy teorii i praktiky), Transport Ukrainy, $368 \mathrm{p}$ (2004). [in Russian] 
9. E. N. Sokol Krushenija zheleznodorozhnyh poezdov (Sudebnaja jekspertiza. Jelementy teorii $i$ praktiki), Feniks, 355 s (2007) [in Russian]

10. Chan $\mathrm{Fu}$ Than. Dinamika gruzovogo vagona pri nelinejnyh svjazjah kuzova s telezhkami: dis. ... d-ra teh. nauk: 05.22.07, Moskva, MIIT. 287 s (2010) [in Russian]

11. W. Huimin, B. Kerchof Management of wheel/rail interface to prevent rail rollover derailments Proceedings of the Institution of Mechanical Engineers, Part F: Journal of Rail and Rapid Transit published online (2014)

12. M. Sebès, L. Chevalier, J. Ayasse, H. Chollet $A$ fastsimplified wheel-rail contact model consistent with perfect plastic materials, Vehicle System Dynamics: International Journal of Vehicle Mechanics and Mobility, 50, pp 1453-1471 (2012)

13. J. Piotrowski, W. Kik A simplified model of wheel/rail contact mechanics for non-Hertzian problems and its application in rail vehicle dynamic simulations, Vehicle System Dynamics, 1-2 (46), pp 27-48 (2008)

14. M. Sysyn, U. Gerber, D. Gruen, O. Nabochenko, V. Kovalchuk Modeling and vehicle based measurements of ballast settlements under the common crossing, European transport, 71 (2019)
15. M. Sysyn, O. Nabochenko, V. Kovalchuk, U. Gerber Evaluation of railway ballast layer consolidation after maintenance works, ACTA Polytechnics, 1 (59), pp 77-87 (2019)

16. J. Kalivoda, L. Neduzha Simulation of Safety Against Derailment Tests of an Electric Locomotive, Proc. of 25th Intern. Conf. «Engineering Mechanics 2019», pp 177-180 (2019)

17. O. Kyryl'chuk, J. Kalivoda, L. Neduzha High Speed Stability of a Railway Vehicle Equipped with Independently Rotating Wheels, Proc. of 24th Intern. Conf. «Engineering Mechanics 2018», pp 473-476 (2018)

18. A. Kuzyshyn, A. Batig, S. Kostritsa [et al.] Research of safety indicators of diesel train movement with two-stage spring suspension, BulTrans 2018: 10th Intern. Sci. Conf. on Aeronautics, Automotive and Railway Engineering and Technologies. - Sozopol: 234 (2018)

19. V. Kovalchuk, A. Kuzyshyn, S. Kostritsa [et al.] Improving a methodology of theoretical determination of the frame and directing forces in modern diesel trains, Eastern-European Journal of Enterprise Technologies, 6/7 (96), pp 19-25 (2018) 